\title{
MEASUREMENT OF ENDOTRACHEAL TUBE CUFF PRESSURE USING A CONVENTIONAL METHOD IN ELECTIVE SURGERIES
}

Kayalvizhi Periyasamy1, Radhika Jayaraman ${ }^{2}$

${ }_{1}^{1}$ Assistant Professor, Department of Anaesthesia, Government Mohan Kumaramangalam Medical College Hospital, Salem, Tamilnadu. ${ }^{2}$ Assistant Professor, Department of Anaesthesia, Government Mohan Kumaramangalam Medical College Hospital, Salem, Tamilnadu.

ABSTRACT
BACKGROUND
Endotracheal intubation is the key to airway management in general anaesthesia. It is essential to maintain an optimum
endotracheal tube cuff pressure in order to achieve optimum seal, thereby preventing the damage to the tracheal mucosa. This
study was done to determine the prevalence of endotracheal tube cuff pressure and the risk factors of overinflation.

\section{MATERIALS AND METHODS}

This cross-sectional study was done among 100 participants who underwent elective surgery under general anaesthesia. The participants were selected by convenient sampling. Trachea was intubated with high volume low pressure cuff. Then, cuff pressure was measured using standard cuff pressure manometer and VBM cuff pressure gauge sensitive for low pressure cuffs. The pressure was measured in centimetres of $\mathrm{H}_{2} \mathrm{O}$. Intracuff pressure of $20-30 \mathrm{cms}$ of $\mathrm{H}_{2} \mathrm{O}$ was set as standard and pressures outside this were adjusted to $30 \mathrm{cms}$ of $\mathrm{H}_{2} \mathrm{O}(22 \mathrm{mmHg})$.

\section{RESULTS}

Majority (46\%) of the participants belonged to 40 - 59 years of age. Majority of the participants (52\%) were males. It was observed that only in $10 \%$ of the participants a normal inflation was achieved. Overinflation occurred in $90 \%$ of the participants.

\section{CONCLUSION}

It is essential to strive to achieve an optimal cuff pressure in order to prevent complications to the tracheal mucosa.

\section{KEYWORDS}

Endotracheal Intubation, High Pressure, Mucosal Damage, Sore Throat, Trachea.

HOW TO CITE THIS ARTICLE: Periyasamy K, Jayaraman R. Measurement of endotracheal tube cuff pressure using a conventional method in elective surgeries. J. Evolution Med. Dent. Sci. 2018;7(15):1837-1839, DOI: 10.14260/jemds/2018/415

\section{BACKGROUND}

Endotracheal tube (ETT) intubation has been the mainstay in general anaesthesia during elective surgeries. It is the optimised technique of airway management and provides as a medium for safe delivery of anaesthetic gases and airway protection during the surgery.[1] There are several techniques of achieving ETT intubation, some of them being used of direct Macintosh laryngoscope, video laryngoscope or laryngeal mask airway intubation. ${ }^{[2]}$ Whichever may be the technique, it is important to maintain an optimum pressure in the ETT cuff.

The role of an ETT cuff is to seal the airway in order to prevent leaks and aspiration of pharyngeal contents into trachea during ventilation. An optimum ETT cuff pressure ensures delivery of the mechanical ventilation tidal volume and simultaneously reducing the risk of aspiration without compromising the tracheal perforation. [3] Achieving ideal endotracheal tube cuff pressure is vital in patients undergoing surgeries under general anaesthesia. Overinflation decreases tracheal perfusion pressure and may cause post intubation sore throat. Under inflation increases

'Financial or Other Competing Interest': None.

Submission 05-02-2018, Peer Review 22-03-2018,

Acceptance 28-03-2018, Published 09-04-2018.

Corresponding Author:

Dr. Radhika Jayaraman,

\#40/1, Vijayaragavachariar Road,

Salem-7,

Tamilnadu.

E-mail: drradhikajayaraman@gmail.com

DOI: $10.14260 /$ jemds $/ 2018 / 415$

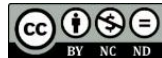

the risk of aspiration of oropharyngeal contents, ventilator failure. ${ }^{[4]}$ Therefore, a minimum pressure of $20 \mathrm{~cm}$ of $\mathrm{H}_{2} \mathrm{O}$ is recommended.

Various devices have been used to measure the ETT cuff pressure in the last few years. The recommendations of the optimum cuff pressure were made by French Society of Critical Care Medicine using a portable manometer.[5] There are several critical acclaims to the manual measurement of the cuff pressure. Conventionally, the clinical method of digital palpation of pilot balloon to achieve ideal pressure has been in vogue. Despite the fact that its efficiency is intensely debated in recent times, the prevailing paucity of studies on this subject on Indian population is worth noting.[3]

\section{Objective}

1. To estimate the mean ETT cuff pressures among the study participants.

2. To evaluate the risk factors for over/ underinflation among the study participants.

\section{MATERIALS AND METHODS Study Setting}

This cross-sectional study was done in the Department of Anaesthesia of our medical college hospital among patients posted for elective surgeries.

\section{Study Population}

Based on the available literature, it was observed that in 31\% of the cases, a normal ETT cuff pressure was achieved. ${ }^{[3]}$ At $95 \%$ level of significance and $10 \%$ absolute precision, the sample size was calculated as 82.13 . Accounting $10 \%$ for non- 
response, the sample size was arrived at 90.3 and was finally rounded off to 100 . The participants were selected by convenient sampling.

\section{Inclusion Criteria}

Patients planned for surgeries under general anaesthesia with cuffed endotracheal tube.

\section{Exclusion Criteria}

Patients with known laryngotracheal abnormalities.

\section{Ethical Approval and Informed Consent}

Approval from the Institutional Ethics Committee was obtained at the commencement of the study. After explaining the procedure and obtaining the informed consent, patients were posted for surgeries under GA with cuffed ETT selected.

\section{Data Collection}

Trachea was intubated with 8.0 or $8.5 \mathrm{~mm}$ CETT in males and 7.0 or $7.5 \mathrm{~mm}$ CETT in females using a disposable SteriMed CETT high volume low pressure cuff. A $10 \mathrm{~mL}$ syringe was used to inflate the cuff. Palpation of pilot balloon was done to confirm satisfactory inflation of cuff. Then cuff pressure was measured using standard cuff pressure manometer, VBM cuff pressure gauge sensitive for low pressure cuffs. The pressure was measured in centimetres of $\mathrm{H}_{2} \mathrm{O}$. Intracuff pressure of 20$30 \mathrm{cms}$ of $\mathrm{H}_{2} \mathrm{O}$ was set as standard and pressures outside this were adjusted to $30 \mathrm{cms}$ of $\mathrm{H}_{2} \mathrm{O}(22 \mathrm{mmHg})$.

\section{Primary Outcome}

Percentage of inflation of cuff within the normal range by clinical method was noted.

\section{Data Analysis}

Data was entered and analysed using SPSS version 22. Percentages were computed for the prevalence of normal/over/underinflation. Chi-square test was carried out to analyse the association between the inflation and risk factors.

\section{RESULTS}

This cross-sectional study was done among 100 participants who were posted for elective surgeries with general anaesthesia. Majority (46\%) of the participants belonged to 40 - 59 years of age. Majority of the participants (52\%) were males. The background characteristics of the study participants are given in Table 1.

\begin{tabular}{|c|c|c|c|}
\hline SL. No. & Characteristics & Frequency $(n=100)$ & $(\%)$ \\
\hline \multirow[t]{5}{*}{1} & \multicolumn{3}{|c|}{ Age (In Years) } \\
\hline & $\leq 20$ & 11 & 11.0 \\
\hline & $20-39$ & 42 & 42.0 \\
\hline & $40-59$ & 46 & 46.0 \\
\hline & $>60$ & 1 & 1.0 \\
\hline 2 & \multicolumn{3}{|c|}{ Sex } \\
\hline & Male & 52 & 52.0 \\
\hline & Female & 48 & 48.0 \\
\hline \multirow[t]{4}{*}{3} & $\begin{array}{l}\text { Body Mass Index } \\
\left(\mathrm{kg} / \mathrm{m}^{2}\right)\end{array}$ & & \\
\hline & $\leq 25.00$ & 50 & 50.0 \\
\hline & $25.01-29.99$ & 45 & 45.0 \\
\hline & $\geq 30.00$ & 5 & 5.0 \\
\hline \multicolumn{4}{|c|}{$\begin{array}{l}\text { Table 1. Background Characteristics of the Study } \\
\text { Participants }\end{array}$} \\
\hline
\end{tabular}

The prevalence of ETT cuff inflation is given in Table 2. It was observed that only in $10 \%$ (4.1 to 15.9) of the participants a normal inflation was achieved. Overinflation occurred in $90 \%$ of the participants.

\begin{tabular}{|c|c|c|c|c|}
\hline $\begin{array}{c}\text { SL. } \\
\text { No. }\end{array}$ & $\begin{array}{c}\text { Type of } \\
\text { Inflation }\end{array}$ & $\begin{array}{c}\text { Frequency } \\
(\mathbf{n = 1 0 0})\end{array}$ & $\begin{array}{c}\text { Percentage } \\
\mathbf{( \% )}\end{array}$ & $\mathbf{9 5 \%}$ CI \\
\hline 1 & Normal & 10 & 10.0 & $4.1-15.9$ \\
\hline 2 & Overinflation & 90 & 90.0 & $84.1-95.9$ \\
\hline 3 & Underinflation & 0 & 0.0 & 0 \\
\hline \multicolumn{4}{|c|}{ Table 2. Prevalence of Types of Inflation among the Study }
\end{tabular}

Participants

The association between the inflation and risk factors are given in Table 3 . Overinflation was present in all the participants who were $<20$ years and $>60$ years. However, the observed difference was statistically not significant. Similarly, males were found to be at increased risk of overinflation (92.3\%) compared to females (87.5\%). However, the observed difference was not significant statistically.

The proportion of range of pressures achieved is depicted in Figure 1. It is observed that in $25 \%$ of the participants the pressure ranged between 51 and $60 \mathrm{~cm}$ of $\mathrm{H}_{2} \mathrm{O}$, while in $23 \%$ of the participants the pressure ranged between 61 and 70 $\mathrm{cm}$ of $\mathrm{H}_{2} \mathrm{O}$.

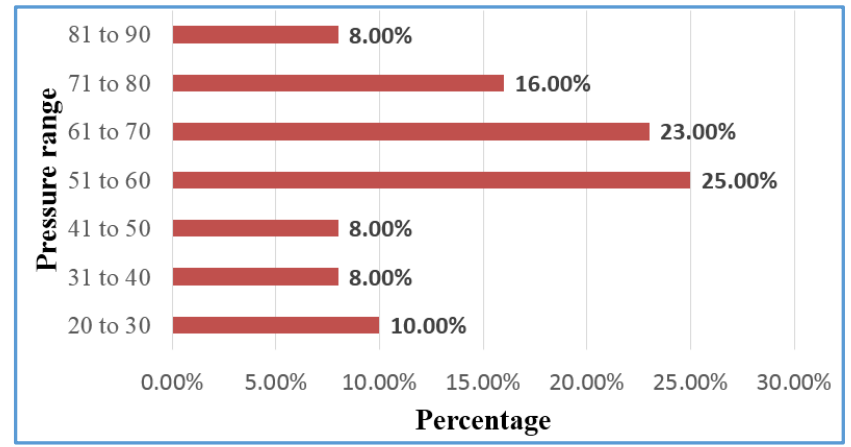

Figure 1. Frequency Distribution of ETT Cuff Pressure among the Study Participants

\begin{tabular}{|c|c|c|c|c|c|c|}
\hline \multirow{2}{*}{$\begin{array}{l}\text { SL. } \\
\text { No. }\end{array}$} & \multirow{2}{*}{$\begin{array}{l}\text { Risk } \\
\text { Factor }\end{array}$} & \multirow{2}{*}{$\mathbf{N}$} & \multicolumn{2}{|c|}{ Overinflation } & \multirow{2}{*}{ Chi-sq. } & \multirow{2}{*}{$\begin{array}{c}P \\
\text { value }\end{array}$} \\
\hline & & & $\mathbf{n}$ & $\%$ & & \\
\hline 1 & $\begin{array}{c}\text { Age } \\
\text { (In Years) }\end{array}$ & & & & & \\
\hline & $\leq 20$ & 11 & 11 & 100 & & \\
\hline & $20-39$ & 42 & 38 & 90.5 & & \\
\hline & $40-59$ & 46 & 40 & 86.9 & & \\
\hline & $>60$ & 1 & 1 & 100 & 1.81 & 0.61 \\
\hline 2 & Sex & & & & & \\
\hline & Male & 52 & 48 & 92.3 & & \\
\hline & Female & 48 & 42 & 87.5 & 0.64 & 0.42 \\
\hline
\end{tabular}

\section{DISCUSSION}

The morbidity associated by an overinflated cuff has been regularly highlighted in literature like, mucosal ulceration, sore throat and hoarseness, tracheal necrosis, rupture and stenosis are all potential risks when intra-cuff pressure is excessively high.

Current clinical methods of endotracheal cuff pressure monitoring are not reliable.[6] Many authors recommended 
routine instrumental monitoring.[3,5,7] In our study also the proportion of subjects achieving normal pressure with clinical method is very low, as in 9 out of 10 persons the cuff pressure was higher than recommended value.

Almost $90 \%$ of the study population- The cuff pressure achieved was higher than recommended. This phenomenon was observed across the age groups, gender and in different BMI categories. It has been established that large volume, low pressure ETT cuffs have less deleterious effect on the tracheal mucosa compared to low volume high pressure ETT cuffs. Animal studies have proven to have lower depths of erosion; however, the area of erosion was larger with low pressure cuffs.

\section{CONCLUSION}

Monitoring cuff pressure by instrumental method can be more effective in achieving ideal cuff pressure and minimising the complications. It is essential to strive to achieve an optimal cuff pressure in order to prevent complications to the tracheal mucosa, which in turn improves the patient's recovery and minimises the hospital stay.

\section{Limitations}

This study did not prospectively assess the impact of overinflation among the study participants due to certain logistic constraints. A larger sample of data could have proven statistical significance of association between overinflation and the risk factors.

\section{REFERENCES}

[1] Durbin CG, Bell CT, Shilling AM. Elective intubation. Respir Care 2014;59(6):825-49.

[2] Fan H, Cao H, Sun Y, et al. Endotracheal intubation in elective cervical surgery. Medicine (Baltimore) 2017;96(43):e7817.

[3] Khan MU, Khokar R, Qureshi S, et al. Measurement of endotracheal tube cuff pressure: instrumental versus conventional method. Saudi Journal of Anaesthesia 2016;10(4):428-31.

[4] Rokamp KZ, Secher NH, Moller AM, et al. Tracheal tube and laryngeal mask cuff pressure during anaesthesia mandatory monitoring is in need. BMC Anesthesiology 2010;10:20.

[5] Nseir S. Endotracheal cuff pressure monitoring: another alarm in the ICU? Am J Crit Care 2011;20(6):422-3, author reply 423-4.

[6] Grant T. Do current methods for endotracheal tube cuff inflation create pressures above the recommended range? A review of the evidence. Journal of Perioperative Practice 2013;23(12):292-5.

[7] Sole ML, Su X, Talbert S, et al. Evaluation of an intervention to maintain endotracheal tube cuff pressure within therapeutic range. American Journal of Critical Care 2011;20(2):109-18. 